\title{
Effects of Adenosine on Mast Cells
}

M.J. Lohse, K.-N. Klotz, K. Maurer, I. Ott, and U. Schwabe

\section{Introduction}

Stimulation of mast cells with appropriate antigen results in the rapid release of a large number of mediators of allergy from the cells. The cells possess cell surface receptors for the Fc portion of IgE which serve to transmit the signal of binding of an antigen by the IgE molecule to the interior of the cell. Since monovalent antigens are not capable of inducing mast cell secretion it is believed that crosslinking of IgE molecules by di-or polyvalent antigens represent the appropriate stimuli (Foreman 1980). These stimuli ultimately result in the release of two groups of mediators of allergy: preformed mediators, and secondary or newly formed mediators. Preformed mediators are stored in the mast cell granules and become released upon fusion of the granules with the plasma membrane; they include histamine, serotonin, chemotactic factors, iysosomal enzymes and heparin. Secondary mediators are synthesized only after stimulation of mast celis and then immediately released; they include prostaglandin $D_{2}$, leukotrienes and platelet activating factor (Siraganian 1983).

Studies of mast cells are complicated by important intraand inter-species differences. Within a species, there appear to be at least two groups of mast cells (reviewed by Enerback 1986). The first group is the connective tissue mast cells, which is the most frequently studied type of mast cells and includes, for example, the mast cells obtained by peritoneal lavage. The second group represents the mucosal mast cells, which differ histologically, functionaliy and in their response to pharmacological agents from those of the first group. Blood basophils are, like mast celis, derived from bone marrow precursors, but their final differentiation in the blood rather than in tissues appears to result in yet another spectrum of properties (Kitamura et al. 1983). This heterogeneity together with differences between species, and often between strains of the same species, or even between the same strains obtained from different suppliers, may explain the discrepant results obtained by different laboratories and should be taken into consideration when generalizing and comparing experimental findings. 
The first evidence that adenosine can alter mast cell mediator release was reported by Marquardt et al. in 1978 . These authors found that adenosine enhanced mast cell release when cells were stimulated with a variety of agents, but that it did not affect release from nonstimulated cells. Since this modulatory effect of adenosine was antagonized by theophylline, it was assumed that it was exerted via classical adenosine receptors. Further supporting the hypothesis of a role for adenosine in the regulation of mast cell mediator release was the observation that antigenstimulated mast cells generate substantial amounts of adenosine, probably via hydrolysis of ATP (Marquardt et al. 1984). This led to the hypothesis of a positive feedback: stimulation of mast cells by antigen (or other stimuli) leads not only to mediator release, but at the same time to generation of adenosine; adenosine, in turn, enhances mediator release by an action at cell surface receptors.

Two findings challenged this straight-forward concept. First, adenosine may not only enhance, but also inhibit mediator release from basophils and mast cells, and sometimes both enhancement and inhibition were seen in the same models depending on experimental conditions (Marone et a). 1979; Church et a 1. 1983; Hughes et al. 1984). Second, whereas earlier studies found that methylxanthines antagonized the enhancing effects of adenosine (Marquardt 1978; Church et al. 1983; Hughes et al. 1984), more recent studies failed to observe such antagonism (Vardey and Skidmore, 1985; Hughes and Church, 1986). These observations suggested that adenosine may exert more complex effects on mast cells than thought previously, and that these effects may occur via as yet unknown sites.

\section{Effects of adenosine on peritoneal mast cells.}

Our initial studies sought to verify the concept that adenosine receptors exist on the surface of mast cells. We used rat peritoneal mast cells, purified to $>95 \%$ homogeneity, as a model. In membranes prepared from these cells, adenosine and several of its analogues stimulated the activity of adenylyl cyclase by $30-50 \%$ (Lohse et al. 1987). Theophyli ine and 8-phenyltheophyline completely prevented this stimulation. In intact mast cells, 5'-N-ethylcarboxamidoadenosine (NECA), caused a two-fold increase in CAMP-levels even in the absence of phosphodiesterase inhibitors. This effect was again antagonized by methylxanthines. These data strongly suggest the presence of adenosine receptors of the $A_{2}$ type on rat pertoneal mast cel1s. No evidence for receptors of the $A_{1}$ type was found in experiments investigating adenyly cyclase activity in membranes, cAMP-levels in intact cells, or in radioligand binding studies (Lohse et al. 1987).

Adenosine analogues enhanced histamine release from the cells, when release was induced by the calcium ionophore A23187 or by the lectin concanavalin $A$ which cross-1inks IgE receptors. The order of potency was NECA>R-PIA $>2-C 1$-adenosine with NECA also beling somewhat more effective than other adenosine analogues. However, in contrast to adenosine receptor-mediated effects, methyixanthines did not 
antagonize the enhancement of histamine release by adenosine analogues (Lohse et al. 1987). A similar lack of antagonism by methylxanthines has been observed by other investigators (Vardey and Skidmore, 1985; Leoutsakos and Pearce 1986; Hughes and Church 1986; Peachel1 et a1. 1989).

These results allow two possible conclusions: either the enhancement of histamine release by adenosine is mediated by a novel type of adenosine receptor, or it occurs via an intracellular site. The first conclusion, i.e. the postulate of a new type of adenosine receptor, was made by Hughes and Church (1986), since they observed no effect of the nucleoside transport inhibitor dipyridomole. our own data, however, support the idea of an intracelluiar site of action of adenosine (Lohse et al.1987, 1988). This hypothesis was based on the effects of two more potent nucleoside transport inhibitors, nitrobenzylthioinosine (NBTI) and nitrobenzylthioguanosine (NBTG). First, these compounds prevented the adenosine-induced enhancement of histamine release from rat peritoneal mast cel1s, when the cells were stimulated either with A23187, or with concanavalin $A$ (Lohse et al. 1987). And second, in the absence of endogenous adenosine but in the presence of strong stimuli such as higher concentrations of A23187, NBTI actualiy enhances histamine release (Lohse et al. 1988, 1989). Since in the presence of strong stimuli considerable amounts of adenosine are generated by mast cells (Marquardt et al. 1984), we think that the release-enhancing effects of NBTI are due to trapping of the newly generated adenosine inside the mast cells. Hence, it is assumed that adenosine enhances histamine release via an action at an intracellular site.

\section{Synergism between adenosine and calcium.}

To further investigate the nature of this presumed intracellular site, we studied the effects of adenosine on the intracellular events that follow antigenic stimulation. Although the exact cascade leading from IgE receptor considerable controversy (see for example penner 1988), it is generally agreed that the initial event is activation of phospholipase c leading to generation of inositol trisphosphate (which releases calcium from intracellular stores) and diacylglycerol (which activates protein kinase
c). Both free cytosolic calcium and protein kinase c are thought to activate mediator release through as yet

In our hands, adenosine and its analogues interfered netther with the generation of inositol trisphosphate nor with the receptors of rat peritonealium after stimulation of the IgE In contrast, Marquardt and Walker (1988, 1989) reported that adenosine increased the cytosolic calcium concentration in antigen-stimulated bone marrow-derived mast cells; it is not
clear, however, whether these authors controlled for the
artifactual signals due to the cells (Almers and Neher 1985). 
Adenosine did, however, enhance histamine release induced by elevated levels of cytosolic calcium (Lohse et al. 1988). This was demonstrated by varying the free calcium concentration in ATP-permeabilized mast cells. Together with the well-known enhancing effects of adenosine on A23187-induced release this suggests that adenosine acts at a step distal to elevation of cytosolic calcium. At this step there appears to be synergism between calcium and adenosine. Not only does adenosine enhance the effects of intraceliular calcium, but in addition elevated intracellular calcium increases the potency of adenosine and its analogues (Lohse et al. 1989).

There is some evidence that adenosine might act via an activation of protein kinase $c$, since adenosine appears to enhance translocation of the kinase, and also because downregulation of the kinase reduces the effects of adenosine (Marquardt and Walker 1989). However, whereas phorbol esters, direct activators of protein kinase c, induce some histamine release by themselves, adenosine clearly has no effect when given alone. Furthermore, adenosine does not enhance the effects of submaximal concentrations of phorbol esters (Lohse et al. 1988).

\section{Effects of adenosine on histamine release from human lung}

tissue.

In order to explore the relevance of these findings to the setting of mediator release from mast cells in the human lung we have more recently studied the effects of adenosine and its analogues on histamine release from human 1 ung fragments obtained during surgery. Histamine release from these fragments was induced by either concanavalin $A$ or A23187. Adenosine and its analogues only slightly stimulated release when given together with these agents. However, in the additional presence of adenosine receptor antagonists, adenosine caused a very marked increase of histamine release. On the other hand, in the presence of nucleoside transport inhibitors adenosine caused an inhibition of histamine release. This suggests that adenosine inhibits histamine release from these fragments via an $\mathrm{A}_{2}$ receptor (as seen in basophils by Marone et al. 1979 , and others) and stimulates the release via an intracellular site. The development of antagonists for this intracellular site may, therefore, result in an inhibition of histamine release in the human lung and lead to the development of novel antiallergic drugs.

\section{References}

Almers, W., Neher, E., 1985, The Ca signal from fura-2 loaded mast cells depends'strongly on the method of dye-loading. FEBS Lett. 192, 13-18.

Church, M.K., Holgate, S.T., Hughes, P.J., 1983, Adenosine inhibits and potentiates IgE-dependent histamine release from human basophils by an $\mathrm{A}_{2}$-receptor mediated mechanism. Br. J. Pharmacol. 80, 719-726.

Enerback, L., 1986, Mast cell heterogeneity: the evolution of the concept of a specific mucosal mast cell. In: Mast Cell Differentiation and heterogeneity, ed. Befus, A.D. et al., Raven Press, New York, pp.1-26. 
Foreman, J., 1980, Receptor-secretion coupling in mast cells. Trends Pharmacoi. Sci. i, 460-462.

Hughes, P.J., Holgate, S.T., Church, M.K., 1984, Adenosine inhibits and potentiates IgE-dependent histamine release from human 1 ung mast cells by an $A_{2}$-purinoceptor mediated mechanism. Biochem. Pharmacol. 33, $3847-3852$.

Hughes, P.J., Church, M.K., 1986, Separate purinoceptors mediate enhancement by adenosine of concanavalin A-induced mediator release and the cyclic AMP response in rat mast cells. Agents and Actions 18, $81-84$.

Leoutsakos, A., Pearce, F.L., 1986, The effect of adenosine and its analogues on cyclic AMP changes and histamine secretion from rat peritoneal mast cells stimulated by various ligands. Biochem. Pharmaco1. 35, 1373-1379.

Lohse, M.J., Maurer, K., Gensheimer, H.-P., Schwabe, U., 1987, Dual effects of adenosine on rat peritoneal mast ceils. NaunynSchmiedeberg's Arch. Pharmacol. 335, 555-560.

Lohse, M.J., Klotz, K.-N., Salzer, M.J., Schwabe, U., 1988, Adenosine regulates the $\mathrm{Ca}^{++}$sensitivity of mast cell mediator release. Proc. Nat1. Acad. Sci. USA 85, 8875-8879.

Lohse, M.J., Maurer, K., Klotz, K.-N., Schwabe, U., 1989, Synergistic effects of calcium-mobilizing agents and adenosine on histamine release from rat peritoneal mast cells. Br. J. Pharmacol. (in press).

Marone, G., Findlay, S.R., Lichtenstein, L.M., 1979, Adenosine receptor on human basophils: Modulation of histamine release. J. Immunol. 123, $1473-1477$.

Marquardt, D.L., Parker, C.W., Sullivan, T.J., 1978, Potentiation of mast cell mediator release by adenosine. J. Immunol. 120,871-878.

Marquardt, D.L., Gruber, H.E., Wasserman, S.I., 1984, Adenosine release from stimulated mast cells. 'Proc. Natl. Acad.' Sci. USA 81, 6192-6196.

Marquardt, D.L., Walker, L.L., 1988, Aiteration of mast cell responsiveness' to adenosine by pertussis toxin. Biochem. Pharmacol. 37, 4019-4025.

Marquardt, D.L., Walker, L.L., 1989, Pretreatment with phorbol esters abrogates mast cell adenosine responsiveness. J. Immuno1. 142, 1268-

Peachei1, P.T., Columbo, M., Kagey-Sobotka, A., Lichtenstein, L.M., Marone, G., 1988, Adenosine potentiates mediator release from human lung mast cells. Am. Rev. Resp. Dis. 138, 1143-1151.

Penner, R., 1988, Multiple signaling pathways control stimulus-secretion coupling in rat peritoneal mast cells. Proc. Nat7. Acad. Sci. USA 85,
$9856-9860$.

Siraganian, R.P., 1983, Histamine-secretion from mast-cells and

basophils. Trends Pharmacol. Sci.4, 432-437.
Vardey, C.J., Skidmore, I.F., 1985, Characterization of the adenosine
receptor rem mast-cells and receptor responsible for the enhancement of mediator release from rat mast cells. In: Purines: Pharmacology and physiological roles, ed.
Stone, T.W., VCH Verlagsgesellschaft, Weinheim, p 175 . 